\title{
Selective Antibody Deficiency with Normal Immunoglobulins
}

National Cancer Institute

\section{Source}

National Cancer Institute. Selective Antibody Deficiency with Normal Immunoglobulins. NCI Thesaurus. Code C85073.

A rare syndrome characterized by deficiency of specific antibodies to polysaccharide antigens while the specific antibodies to protein antigens are normal. 